\title{
PERANCANGAN MESIN PENGOLAH LIMBAH STYROFOAM DENGAN METODE SABUK PEMANAS
}

\author{
Design of Styrofoam Waste Processing Machine with Heating Belt Method
}

Tri Mulyanto*, Supriyono dan Rian Adi Gunawan

Universitas Gunadarma, Jl. Margonda Raya no. 100, Indonesia

Informasi artikel

Diterima: 05/04/2020

Direvisi : 10/04/2020

Disetujui: 12/04/2020

\begin{abstract}
Abstrak
Styrofoam telah banyak digunakan sebagai kemasan atau pembungkus. Limbah produk-produk ini mengakibatkan polusi lingkungan karena sifatnya yang sulit terurai secara alami dan jika dalam penangannya tidak baik, maka akan menghasilkan zat berbahaya ke udara. Pada penelitian ini digunakan metode perancangan Pahl \& Beitz untuk merancang mesin pengolah limbah styrofoam dengan metode sabuk pemanas, mesin akan dapat mengolah limbah styrofoam menjadi bahan baku produk berbahan plastik. Cara kerja mesin menggunakan prinsip ekstrusi, dimana styrofoam dicacah kemudian diekstrusi melalui sabuk pemanas agar mencapai titik leleh, kemudian dialirkan melalui cetakan untuk menghasilkan produk dengan bentuk penampang sesuai penampang cetakan. Hasil perancangan diperoleh mesin pengolah limbah styrofoam dengan metode sabuk pemanas yang digerakkan motor listrik 750 Watt dengan putaran $1400 \mathrm{rpm}$ dan kapasitas rencana 15,26 $\mathrm{kg} / \mathrm{jam}$.
\end{abstract}

Kata Kunci: ekstrusi, limbah styrofoam, metoda sabuk pemanas, pencacah perancangan.

\begin{abstract}
Styrofoam has been widely used as packaging or wrapping. The waste of these product causes environmental pollution due to its nature which is difficult to decompose naturally and if in the handling is not good, it will produce harmful substances into the air. In this research, using Pahl \& Beitz for design method to design a styrofoam waste treatment machine is designed with a heating belt method, the machine will be able to process styrofoam waste into plastic raw material products. The workings of the machine use the principle of extrusion, where the styrofoam is chopped and then extruded through a heating belt to reach the melting point, then flowed through the mold to produce the product in the form of a cross section according to the cross section of the mold. The design results obtained styrofoam waste processing machines with a heating belt method driven by a 750 Watt electric motor with $1400 \mathrm{rpm}$ rotation and a planned capacity of $15.26 \mathrm{~kg} / \mathrm{hour}$.
\end{abstract}

Keywords: extrusion, styrofoam waste, heating belt method, design counter. 


\section{PENDAHULUAN}

Penggunaan kemasan makanan saat ini di Indonesia berkembang dengan pesat dan variatif, yang awalnya hanya terbuat dari bahan berasal dari alam seperti, alang-alang, rumput, dan kulit kayu. Perkembangan teknologi menyebabkan bahan yang digunakan sebagai kemasan memiliki banyak jenis seperti kardus, plastik yang berbentuk mika, styrofoam dan sebagainya.

Peranan kemasan semula hanya sebatas untuk melindungi, mencegah atau mengurangi terjadinya kerusakan-kerusakan pada produk yang dikemas atau yang dibungkusnya. sekarang kemasan juga digunakan untuk mempermudah produk untuk dibawa. Fungsi kemasan selalu mengikuti dengan kebutuhan para konsumen seperti mudah dibawa, ringan, praktis, tidak mudah tumpah, dengan bentuk yang menarik.

Peranan kemasan suatu produk saat ini tidak hanya sebatas melindungi produk tersebut, tetapi juga menjadi salah satu strategi dagang yang dilakukan oleh para produsen produk makanan tersebut. Sekarang kemasan sudah menjadi salah satu ujung tombak pemasaran yang langsung berhadapan dengan konsumen. Karena itu, kemasan harus dapat menimbulkan ketertarikan calon konsumen melalui bentuk kemasan (Nyoman, 2017).

Di era modern salah satu kondisi yang dijadikan alasan oleh para produsen makanan cepat saji menggunakan kemasan styrofoam karena dianggap sebagai pilihan alternatif yang sangat sesuai dengan keadaan saat ini contohnya mie, bubur ayam, baso, sayuran, dan lain lain. Kemasan styrofoam mempunyai kelebihan bisa menahan kehangatan suhu dari makanan yang dibungkusnya, tahan air, juga mudah diperoleh, cepat disajikan, tidak mudah rusak, harga terjangkau, dan juga kemasan yang ringan. Sehingga styrofoam dapat digunakan sebagai kemasan dari makanan panas ataupun dingin (Pulungan, 2018).

Dengan peningkatan pemakaian styrofoam, akan meningkatkan jumlah sampah dan mengakibatkan adanya penurunan kualitas lingkungan. Karena itu sampah styrofoam merupakan salah satu permasalah besar yang harus segera diatasi. Styrofoam merupakan salah satu olahan dari polystyrene yang merupakan bentukan senyawa styrene yang menggunakan benzena dalam pengolahannya. Sampah styrofoam ini tergolong dalam sampah anorganik yang sulit terurai dan berdampak buruk bagi kesehatan serta lingkungan (Wirahadi, 2017).

Penanganan limbah styrofoam selama ini dilakukan dengan cara penggunaan kembali tanpa melalui modifikasi, pembakaran, dan ditimbun dalam tanah. Salah satu teknologi pemanfaatan limbah styrofoam yang ada saat ini adalah menjadi dinding ringan seperti Hebel, panel (Santoso, 2011), limbah styrofoam dijadikan lem lateks (Maryani, 2018), atau flokulan dalam proses penjernihan air (Listyarini, 2005) dan berbagai penelitian lainnya. Cara-cara pengolahan tersebut merupakan metode konvensional yang tidak ramah lingkungan.

Pengembangan mesin pengolah styrofoam sudah pernah dilakukan sebelumnya. Terdapat dua metode pengembangan yang pernah dilakukan sebelumnya, yaitu dengan metode pemanasan menggunakan sabuk pemanas dan metode peleburan dengan bahan bakar gas. Pengolahan dengan metode sabuk pemanas memiliki hasil keluaran belum sempurna, dikarenakan suhu pemanasan yang dicapai tidak sesuai dengan yang diharapkan, juga karena kurangnya gaya penekanan di dalam tabung pemanas sehingga hanya beberapa bagian yang mencair. Sedangkan pengolahan dengan metode peleburan meng-gunakan bahan bakar gas, kekurangannya adalah suhu peleburan yang sulit di kontrol dan lubang hasil keluaran yang terlalu besar, sehingga ada bagian styrofoam yang belum mencair ikut masuk ke dalam cetakan (Mahmudi, 2017).

Dari paparan diatas, masih perlu upaya lanjutan dalam pengolahan limbah styrofoam yang lebih baik lagi. Sehingga permasalahan lingkungan yang timbul dapat teratasi setidaknya dikurangi. Tujuan dari penelitian ini adalah mendapatkan rancangan mesin pengolah limbah styrofoam dengan metode sabuk pemanas.

\section{METODOLOGI}

Penelitian dimulai dengan membandingkan kedua metode, dimana masing-masing memiliki kelebihan dan kekurangan. Berdasar-kan analisis awal dipilih metode sabuk pemanas untuk penelitian mesin pengolah limbah styrofoam, karena panas yang dihasil-kan tidak terjadi radiasi keluar.

Selanjutnya disusun garis besar tahapan penelitian dengan memodifikasi metode perancangan Pahl dan Beitz (Hurst, 2004), 
yang dijelaskan dengan diagram alir pada Gambar 1.

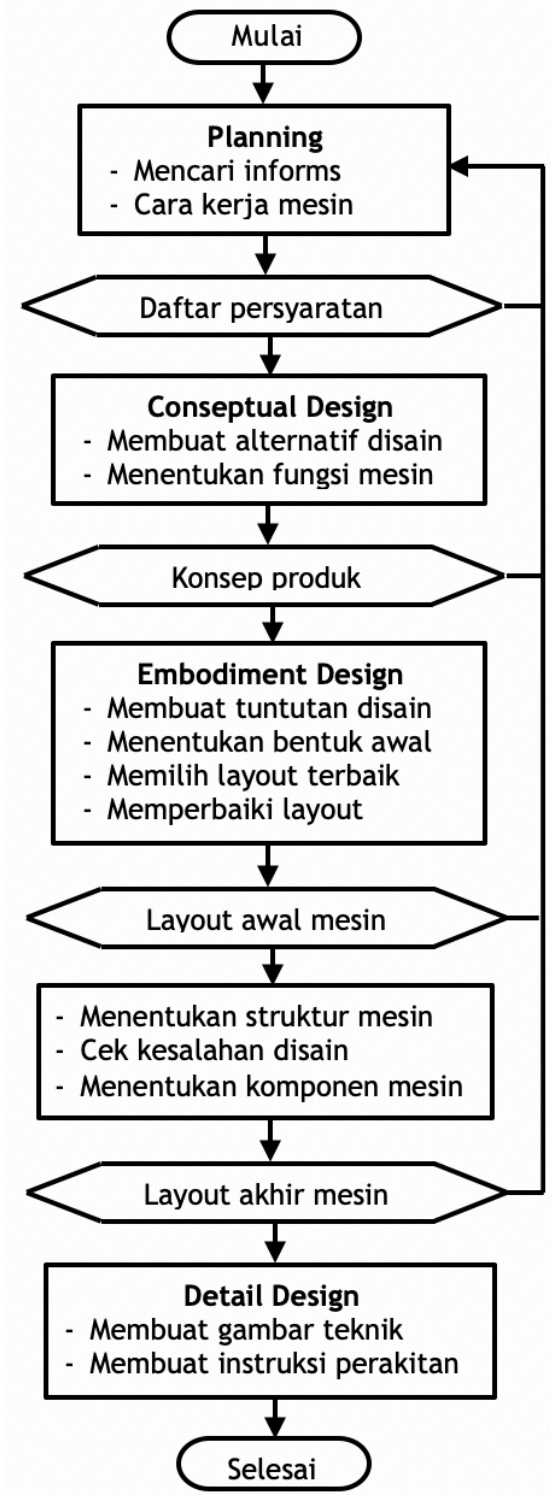

Gambar 1 Diagram Alir Penelitian

Metode perancangan Pahl dan Beitz tersebut terdiri dari 4 fase yang terdiri dari beberapa langkah, ke-empat fase tersebut adalah :

1. Perencanaan dan penjelasan (Planning)

2. Perancangan konsep produk (Conceptual Design)

3. Perancangan bentuk produk (Embodiment Design)

4. Perancangan detail (Detail Design)

Dalam penelitian ini dirancang mesin pengolah limbah styrofoam dengan metode ekstrusi, mesin ini dapat mengolah limbah styrofoam menjadi bahan baku produk untuk kapasitas kecil. Secara umum ekstrusi pada termoplastik adalah suatu proses pembentukan material dengan cara dipanaskan hingga mencapai titik leleh dan melebur akibat panas dari luar atau akibat panas gesekan yang kemudian dialirkan ke cetakan oleh screw untuk menghasilkan material dengan bentuk penampang sesuai dengan bentuk lubang cetakan/die (Kalpakjian, 2000).

\section{HASIL DAN PEMBAHASAN}

\section{Hasil Perencanaan}

Tahap ini meliputi penjelasan rancangan dari mesin, pengumpulan informasi permasalahan dan kendala yang dihadapi. Kemudian mengamati cara kerja mesin serta dilanjutkan dengan persyaratan mengenai sifat dan performa tuntutan produk yang harus dimiliki untuk mendapatkan pengembangan solusi utama seperti pada tabel 1.

Tabel 1 Daftar Persyaratan

\begin{tabular}{lll}
\hline Parameter & \multicolumn{1}{c}{ Spesifikasi } & D/W \\
\hline Geometri & a. Dimensi minimum & D \\
& b. Rangka kokoh & D \\
\hline Energi & a. Motor listrik & D \\
& b. Hemat energi & W \\
\hline Kinematika & a. Mudah dioperasi & D \\
& b. Arah putaran sesuai & D \\
\hline Material & a. Mudah didapat & D \\
& b. Tahan lama & D \\
\hline Ergonomi & a. Mudah operasi & D \\
& b. Bentuk proporsional & W \\
\hline Produksi & a. Komponen sedikit & D \\
& b. Mudah dibuat & D \\
\hline Operasi & a. Aman operasi & D \\
& b. Mudah perawatan & D \\
\hline
\end{tabular}

Selanjutnya membuat daftar prinsip solusi untuk menyeleksi komponen yang akan digunakan dalam mewujudkan desain prototipe mesin pengolah limbah styrofoam dengan metode sabuk pemanas.

\section{Hasil Perancangan Konsep Produk}

Prinsip solusi telah dibuat, maka perlu dilakukan kombinasi yang mungkin, sehingga terbentuk suatu sistem yang paling menunjang dalam bentuk beberapa varian seperti yang ditunjukkan pada tabel 2 .

Berdasarkan prinsip-prinsip solusi yang telah dilakukan di tabel 2, dapat diperoleh konsep produk dengan beberapa variasi:

- Konsep 1: $\mathrm{A} 1 \rightarrow \mathrm{A} 2 \rightarrow \mathrm{A} 3 \rightarrow \mathrm{A} 4 \rightarrow \mathrm{B} 5 \rightarrow \mathrm{B} 6 \rightarrow \mathrm{A} 7 \rightarrow \mathrm{A} 8$

- Konsep 2: $\mathrm{A} 1 \rightarrow \mathrm{A} 2 \rightarrow \mathrm{B} 3 \rightarrow \mathrm{A} 4 \rightarrow \mathrm{A} 5 \rightarrow \mathrm{C} 6 \rightarrow \mathrm{A} 7 \rightarrow \mathrm{B} 8$

- Konsep 3: $\mathrm{B} 1 \rightarrow \mathrm{B} 2 \rightarrow \mathrm{B} 3 \rightarrow \mathrm{A} 4 \rightarrow \mathrm{A} 5 \rightarrow \mathrm{C} 6 \rightarrow \mathrm{A} 7 \rightarrow \mathrm{B} 8$ 
Tabel 2 Kombinasi Prinsip Solusi

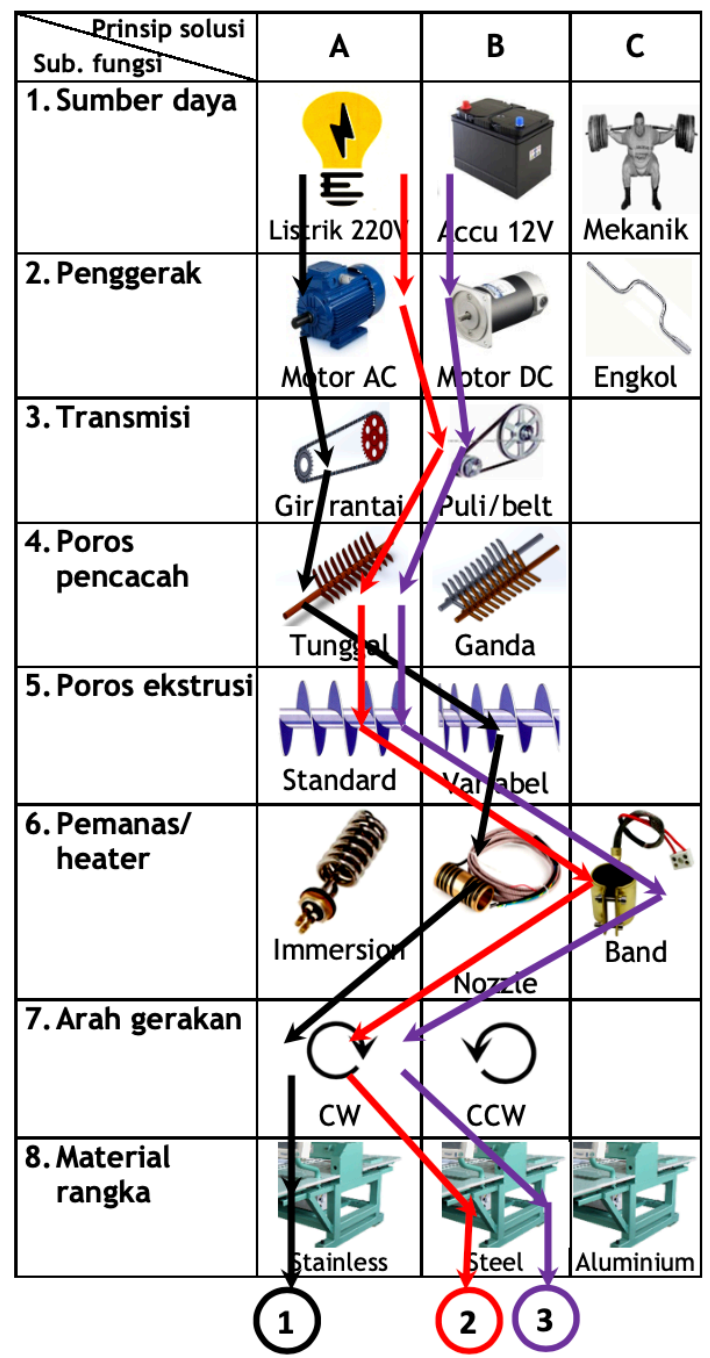

Hasil Perancangan Bentuk Produk

Selanjutnya menentukan konsep produk yang mungkin dilanjutkan dalam proses disain, untuk itu harus dilakukan seleksi terhadap varian yang ada. Salah satu cara dalam pemilihan konsep produk dapat dilakukan dengan menggunakan metode matriks pengambilan keputusan. Metode ini terbukti dapat digunakan secara mudah dan efektif, terutama untuk evaluasi konsep produk yang belum dapat dibandingkan dengan persyaratan teknis secara langsung.

Untuk setiap alternatif konsep produk diberikan nilai. Nilai yang tertinggi adalah 10. Kemudian dari penilaian tersebut, konsep produk yang dipilih adalah konsep produk yang memiliki nilai tertinggi.
Tabel 3 Matriks Keputusan untuk Memilih Konsep Produk

\begin{tabular}{|c|c|c|c|c|c|}
\hline No & $\begin{array}{c}\text { Kriteria } \\
\text { perbandingan }\end{array}$ & $\begin{array}{c}\text { Bobot } \\
\text { nilai } \\
\text { maks }\end{array}$ & $\mathrm{K}-1$ & $\mathrm{~K}-2$ & $\mathrm{~K}-3$ \\
\hline 1 & $\begin{array}{l}\text { Penggunaan } \\
\text { energi }\end{array}$ & 10 & 10 & 10 & 10 \\
\hline 2 & Besar produk & 10 & 9 & 9 & 9 \\
\hline 3 & $\begin{array}{l}\text { Komponen tidak } \\
\text { banyak }\end{array}$ & 6 & 6 & 6 & 6 \\
\hline 4 & $\begin{array}{l}\text { Biaya material } \\
\text { murah }\end{array}$ & 5 & 3 & 5 & 5 \\
\hline 5 & $\begin{array}{l}\text { Biaya } \\
\text { pembuatan }\end{array}$ & 8 & 6 & 8 & 6 \\
\hline 6 & $\begin{array}{l}\text { Pengoperasian } \\
\text { mudah }\end{array}$ & 8 & 8 & 8 & 7 \\
\hline 7 & $\begin{array}{l}\text { Pemeliharaan } \\
\text { mudah }\end{array}$ & 8 & 6 & 8 & 7 \\
\hline 8 & $\begin{array}{l}\text { Keamanan } \\
\text { pengoperasian }\end{array}$ & 8 & 8 & 8 & 7 \\
\hline 9 & Kehandalan & 9 & 9 & 9 & 9 \\
\hline \multirow[t]{2}{*}{10} & $\begin{array}{l}\text { Noise dan } \\
\text { getaran kecil }\end{array}$ & 8 & 5 & 7 & 7 \\
\hline & Jumlah : & 80 & 70 & 78 & 73 \\
\hline
\end{tabular}

Dalam perancangan mesin pengolah limbah styrofoam dengan metode sabuk pemanas kriteria perbandingan dari tabel 3 disusun berdasarkan keinginan dan kebutuhan sebagai berikut:

1. Penggunaan energi : Diinginkan dalam penggunaan energi sedikit mungkin.

2. Besar produk: Diinginkan mesin yang dibuat tidak memiliki bentuk yang begitu besar sehingga tidak terlalu berat.

3. Komponen tidak banyak: Diinginkan komponen tidak banyak untuk memudah-kan perakitan, pemeliharaan serta biaya pembuatan yang menjadi murah.

4. Biaya material murah : Diinginkan biaya diperlukan untuk penyediaan material seminimal mungkin.

5. Biaya pembuatan : Diinginkan biaya yang dikeluarkan untuk memproduksi mesin harus seminimal mungkin.

6. Pengoperasian mudah : Diinginkan biaya untuk pengoperasian semurah mungkin. 
7. Pemeliharaan mudah : Diinginkan perawa-tannya tidak begitu sulit agar alat tetap bekerja dengan baik.

8. Keamanan pengoperasian : Diinginkan mesin harus aman selama dioperasikan.

9. Kehandalan : Diinginkan mesin harus memliki kehandalan yang baik sehingga sehingga akan mengurangi biaya perbaikan.

10. Noise dan getaran yang dihasilkan kecil : Diinginkan pada saat bekerja alat tersebut tidak menghasilkan kebisingan (noise) dan getaran yang tidak terlalalu besar.

Dari beberapa alternatif konsep produk yang dibuat di atas dan dengan informasi tersebut selanjutnya dipilih salah satunya sebagai konsep produk yang akan dibuat. Pada tabel 3 terlihat bahwa varian dapat diketahui jumlah nilai yang dihasilkan dari masing-masing varian, dimana nantinya yang mempunyai nilai tertinggi akan dipilih sebagai komponen yang akan digunakan pada perancangan mesin pengolah limbah styrofoam.

Dengan memperhatikan perhitungan maka yang akan diwujudkan sesuai batasan perancangan, pemilihan komponen yang mudah didapatkan, dipilih varian 2 . Konsep 2 terdiri dari sumber daya listrik, penggerak motor listrik, transmisi puli-belt, poros pencacah tunggal, poros ekstrusi standar, pemanas band, gerakan berputar searah jarum jam dan rangka terbuat dari baja.

Konsep 2 hasil dari perancangan bentuk produk diperoleh layout awal seperti gambar 2 berikut:

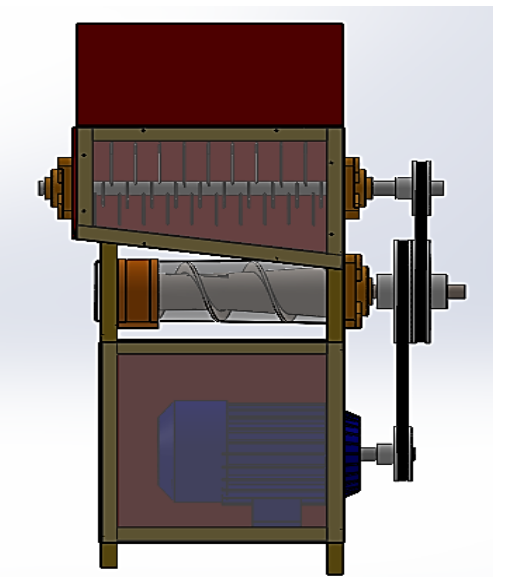

Gambar 2 Mesin Pengolah Limbah Styrofoam

Struktur rangka mesin pengolahan limbah styrofoam merupakan salah satu perangkat utama pada mesin tersebut, dimana rangka ini berfungsi untuk menopang komponen-komponen utama dan pendukung yang terdapat pada mesin pengolahan limbah styrofoam. Komponen utama yang akan ditopang adalah motor listrik dan komponenkomponen lainnya.

Struktur rangka mesin harus menyesuaikan dari tujuan perancangan. Pada penelitian ini, mesin pengolahan limbah styrofoam diperuntukkan dalam skala rumah tangga, maka desain harus minimalis dan menarik dilihat, seperti pada gambar 3 .

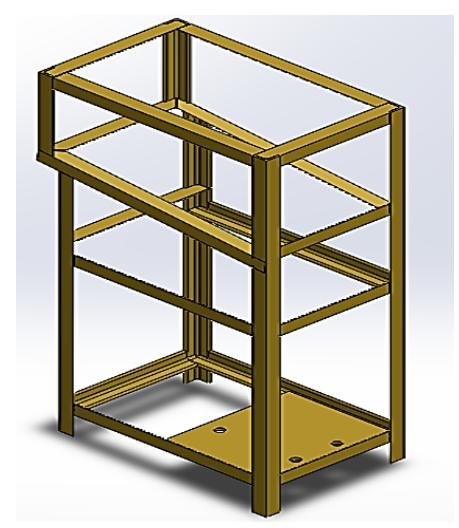

Gambar 3 Rangka Mesin

Motor merupakan pusat dari gerakan dalam keseluruhan sistem, maka dari itu harus diperhatikan dan diperhitungkan dengan teliti dan benar agar sistem yang dirancang dapat berjalan sesuai dengan yang diharapkan, diketahui:

- Daya elektro motor $=750 \mathrm{Watt}$

- Putaran elektro motor $=1400 \mathrm{rpm}$

Pada mesin pengolah limbah styrofoam ini terdapat dua buah poros (lihat gambar 4), yaitu:

1. Poros 1 untuk pencacah styrofoam menggerakkan bilah/pisau pencacah.

2. Poros 2 untuk ekstrusi styrofoam menggerakkan poros ulir.

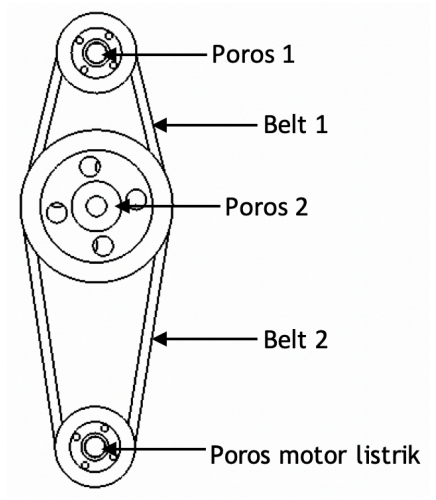

Gambar 4 Transmisi Mesin 
Sistem transmisi pada mesin pengolah limbah styrofoam adalah dengan puli-belt, dengan putaran motor 1400 rpm. Data-data puli pada mesin yang dirancang sesuai yang ada dipasaran untuk menghebat biaya produksi:

1. Puli motor penggerak $\varnothing 80 \mathrm{~mm}$

2. Puli pada pisau pencacah $\varnothing 145 \mathrm{~mm}$

3. Puli pada screw press $\emptyset 550 \mathrm{~mm}$

Dengan mengabaikan slip pada sabuk maka jumlah putaran pada masing-masing puli adalah sebagai berikut (Khurmi, 2005):

1. Putaran poros ekstrusi.

$$
\begin{aligned}
n_{\text {ekstrusi }} & =\frac{n_{\text {motor }} \times d_{\text {motor }}}{d_{\text {ekstrusi }}} \\
& =\frac{1400 \times 80}{550} \\
& =203,6 \mathrm{rpm}
\end{aligned}
$$

2. Putaran poros pencacah.

$$
\begin{aligned}
n_{\text {pencacah }} & =\frac{n_{\text {ekstrusi }} \times d_{\text {ekstrusi }}}{d_{\text {pencacah }}} \\
& =\frac{203,6 \times 550}{145} \\
& =772,4 \mathrm{rpm}
\end{aligned}
$$

Karena daya motor $750 \mathrm{~W}$ dan putaran $1400 \mathrm{rpm}$, maka tipe sabuk dipilih A (Sularso, 1994). Kecepatan linear sabuk dapat dihitung dengan persamaan sebagai berikut:

$$
\begin{aligned}
V & =\frac{\pi \times d_{\text {motor }} \times n_{\text {motor }}}{60 \times 1000} \\
& =\frac{\pi \times 80 \times 1400}{60 \times 1000} \\
& =5,86 \mathrm{~m} / \mathrm{s}
\end{aligned}
$$

Jarak sumbu poros motor dengan poros ekstrusi $(C)$ direncanakan 2 kali diameter puli besar, maka panjang sabuk rencana $(L)$ dapat dihitung sebagai berikut:

$$
\begin{aligned}
L & =2 C+\frac{\pi}{2}\left(d_{m}+d_{p}\right)+\frac{1}{4 C}\left(d_{p}-d_{m}\right)^{2} \\
& =2.1100+\frac{\pi}{2}(80+550)+\frac{1}{4.1100}(550-80)^{2} \\
& =2200+989,1+50,5=3239,6 \mathrm{~mm}
\end{aligned}
$$

Jarak sumbu poros pencacah dengan poros ekstrusi (C) direncanakan 1,8 kali diameter puli besar, maka panjang sabuk rencana $(L)$ dapat dihitung sebagai berikut:

$$
L=2 C+\frac{\pi}{2}\left(d_{m}+d_{p}\right)+\frac{1}{4 C}\left(d_{p}-d_{m}\right)^{2}
$$

$$
\begin{aligned}
& =2.990+\frac{\pi}{2}(145+550)+\frac{1}{4.990}(550-145)^{2} \\
& =1980+1091,15+42,27=3113,4 \mathrm{~mm}
\end{aligned}
$$

Berat per meter panjang sabuk tipe $A=$ 1,06 N (Khurmi, 2005), maka gaya tarikan sentrifugal sabuk adalah:

$$
\begin{aligned}
F_{c} & =m \cdot v^{2} \\
& =1,06 \times(5,86)^{2}=36,4 \mathrm{~N}
\end{aligned}
$$

maka torsi yang didapat:

$$
\begin{aligned}
T & =F_{c} \times l \\
& =36,4 \times 0,08=2,9 \mathrm{Nm}
\end{aligned}
$$

Daya motor yang dibutuhkan adalah:

$$
\begin{aligned}
P & =\frac{2 \pi n \times T}{60} \\
& =\frac{2 \pi 1400 \times 2,9}{60} \\
& =425 \text { Watt }=4,25 \mathrm{~kW}
\end{aligned}
$$

Daya motor tersedia $=750 \mathrm{~W}>$ daya motor yang dibutuhkan $425 \mathrm{~W}$ sehingga motor dapat digunakan. Torsi maksimum yang ditransmisi-kan melebihi torsi rata-rata $20 \%$. Maka torsi maksimum diambil:

$$
\begin{aligned}
T_{\text {mak }} & =\frac{60 \cdot P}{2 \cdot \pi \cdot n} \cdot 1,2 \\
& =\frac{60 \cdot 750}{2 \cdot \pi \cdot 1400} \cdot 1,2 \\
& =6,14 \mathrm{Nm}
\end{aligned}
$$

Dengan poros terbuat dari mild steel dengan tegangan geser maksimum yang diijinkan $42 \mathrm{MPa}$, maka diameter poros pisau pencacah adalah:

$$
\begin{aligned}
d^{3} & =\frac{T_{\text {mak }}}{\frac{\pi}{16} \cdot \tau} \\
& =\frac{6140}{\frac{\pi}{16} \cdot 42} \\
& =744,91
\end{aligned}
$$

$d=9,1 \mathrm{~mm}$ diambil $10 \mathrm{~mm}$

\section{Dimensi Poros Pemecah}

Pisau pencacah yang digunakan harus dapat mencacah bongkahan styrofoam menjadi cacahan-cacahan kecil sehingga memudahkan dalam proses pemanasan. 


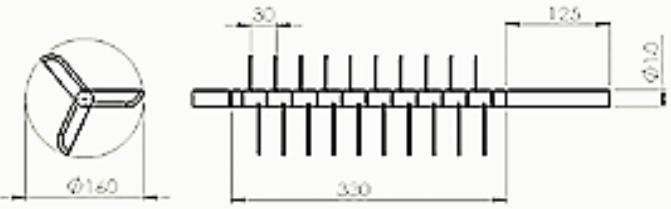

Gambar 5 Poros Pencacah

Gambar 5 memperlihatkan dimensi bagian poros pencacah dari hasil perhitungan yang telah dilakukan sebelumnya.

\section{Dimensi Poros Ekstrusi}

Poros ekstrusi adalah komponen yang berfungsi untuk mendorong styrofoam yang telah dicacah agar bisa masuk ke bagian pemanas atau output seperti terlihat pada gambar 6 .
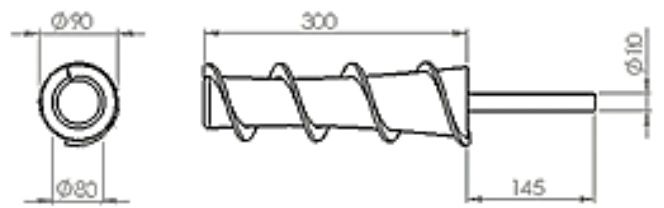

Gambar 6 Poros Ekstrusi

\section{Dimensi Hopper}

Mesin pengolah limbah styrofoam ini dirancang hanya untuk 1 orang operator saja, sehingga dimensi rumah pencacah harus semaksimal mungkin dapat menampung limbah styrofoam yang ada. Untuk itu rumah pencacah direncanakan dengan dimensi rumah pencacah $330 \mathrm{~mm} \times 200 \mathrm{~mm} \times 165 \mathrm{~mm}$, seperti pada gambar 7 yang merupakan rancangan rumah pencacah.

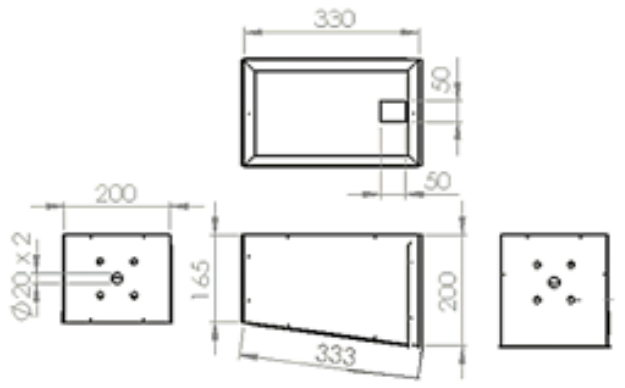

Gambar 7 Dimensi Rumah Pencacah

Dalam menentukan kapasitas mesin pengolah limbah styrofoam ini, dipengaruhi oleh lubang masuk (hopper) ke ruang ekstrusi dan putaran poros ekstrusi. Luas lubang hopper dirancang $=50 \mathrm{~mm} \times 50 \mathrm{~mm}=2500$ $\mathrm{mm}^{2}$, putaran poros ekstrusi $=203,6 \mathrm{rpm}=$ $3,39 \mathrm{rev} / \mathrm{s}$. Kecepatan turun styrofoam diasumsikan $=$ tinggi ulir $=(90-80) / 2 \mathrm{~mm} / \mathrm{rev}$ $=5 \mathrm{~mm} / \mathrm{rev}$ tiap putaran, maka kecepatan pencacahan:

$$
\begin{aligned}
v & =3,39 \mathrm{rev} / \mathrm{s} \times 5 \mathrm{~mm} / \mathrm{rev} \\
& =16,95 \mathrm{~mm} / \mathrm{s}
\end{aligned}
$$

maka kapasitas mesin adalah:

$$
\begin{aligned}
Q & =v \cdot A \\
& =16,95 \mathrm{~mm} / \mathrm{s} .2500 \mathrm{~mm}^{2} \\
& =42,38 \mathrm{~mm}^{3} / \mathrm{s} \\
& =42,38 \times 10^{-6} \mathrm{~m}^{3} / \mathrm{s}
\end{aligned}
$$

Jika massa jenis styrofoam $=100 \mathrm{~kg} / \mathrm{m}^{3}$, maka :

$$
\begin{aligned}
& Q=42,38 \times 10^{-6} \mathrm{~m}^{3} / \mathrm{s} .100 \mathrm{~kg} / \mathrm{m}^{3} \\
& =42,38 \times 10^{-4} \mathrm{~kg} / \mathrm{s} \\
& =15,26 \mathrm{~kg} / \mathrm{jam}
\end{aligned}
$$

\section{Hasil Perancangan Detail}

Hasil perancangan detail berupa dokumen yang meliputi gambar mesin, detail gambar mesin, daftar komponen, spesifikasi bahan, sistem pengoperasian, toleransi dan dokumen lainnya yang merupakan satu kesatuan. Berdasarkan perencanaan dan hasil perhitung-an untuk mesin pengolah limbah styrofoam diperoleh beberapa data sebagai acuan dalam mendesain mesin tersebut. Proses perencanaan dan perhitungan sangat mempengaruhi kekuatan dan efisiensi mesin.

\section{SIMPULAN}

Perancangan ini telah dihasilkan suatu mesin pengolah limbah styrofoam dengan metode sabuk pemanas yang bekerja dengan cara ekstrusi. Proses pengolahan limbah styrofoam dicacah lalu di ekstrusi melalui sabuk pemanas sehingga keluar melalui cetakan. Kapasitas rencana mesin 15,26 $\mathrm{kg} / \mathrm{jam}$ dengan digerakkan motor listrik 750 Watt dengan putaran $1400 \mathrm{rpm}$.

\section{DAFTAR PUSTAKA}

Hurst, Kenneth S, 2004, Engineering Design Principles, Oxford: Elsevier Ltd.

Kalpakjian, Serope, Steven R. Schmid, 2000, Manufacturing Engineering and Technology, fourth edition, New Delhi, Addison Wesley.

Khurmi, R.S dan Gupta, JK. 2005, A Text Book of Machine Design. New Delhi: Eurasia Publishing House (prt) Ltd.

Listyarini, A., 2005, Pemanfaatan Limbah Styrofoam Sebagai Flokulan Dalam Proses Penjernihan Air Melalui Proses 
Sulfonisasi, Jurnal Kimia dan Kemasan, Vol. 27, No. 2, pp 14-20.

Mahmudi, A., Petrus Londa, 2017, Optimasi Penerapan Teknologi Ekstrusi pada Prototipe Mesin Daur Ulang Limbah Styrofoam, Jurnal Rotasi, Vol. 19, No. 2, pp 92-96.

Maryani, Y., Nufus Kanani, Rusdi, 2018, Pembuatan Lem Lateks Dari Limbah Styrofoam Yang Digunakan Untuk Kemasan Makanan, Jurnal Teknika, Vol. 12, No. 2, pp 189-200.

Nyoman, I Sucipta, Ketut Suriasih, dan Pande Ketut Diah Kencana, 2017, Pengemasan Pangan (Kajian Pengemasan Yang Aman, Nyaman, Efektif Dan Efisien), Denpasar, Udayana University Press.

Pulungan, H. Maimunah, et al, 2018, Teknologi Pengemasan dan Penyimpanan, Malang, UB Press.

Santoso, A., Slamet Widodo dan Faqih Ma'arif, 2011, Pemanfaatan Limbah Styrofoam (Expanded Polysterene) Untuk Pembuatan Dinding Struktural Beton Ringan Ramah Lingkungan, Jurnal Inersia, Vol. VII No. 1, pp 1-18.

Sularso dan Kiyokatsu Suga, 1994, Dasar Perencanaan dan Pemilihan Elemen Mesin. Jakarta, Pradnya Paramita.

Wirahadi, Michelli, 2017, Elemen Interior Berbahan Baku Pengolahan Sampah Styrofoam dan Sampah Kulit Jeruk, Jurnal Intra, Vol. 5, No. 2, pp 144-153. 